\title{
Examining the Satisfaction and Values of Domestic and International Marriages
}

\author{
Stephanie J. Thorson-Olesen \\ Viterbo University, LaCrosse, USA
}

\begin{abstract}
Despite an emphasis on global interconnectedness, little has been written about the unique challenges of international marriages. As a result, this research was conducted to investigate the marital values and satisfaction of males and females in domestic (natives of the U.S.) and international (one is a native of the U.S. and the other is foreign born) marriages. The Characteristics of Marriage Inventory (CHARISMA) was used to gather information through an online quantitative survey. The mean family values score for American participants with American spouses (domestic marriage) was significantly higher than the mean family values score for foreign-born participants with American spouses (in an international marriage). However, there was no significant difference in marriage satisfaction. In addition, an analysis of gender resulted in a non-significant effect on the combined marital satisfaction variable, but indicated a significant main effect on loyalty. The mean loyalty score for male participants (both native born and international) was significantly lower than the mean loyalty score for female participants. As a result, it is important for further research to understand what loyalty means to men (domestic and international). Moreover, psychology must further explore the values of the international married population and examine the context of a marriage.
\end{abstract}

Keywords: international marriage, marital satisfaction, marital values

In recent decades, the degree and intensity of the connectedness of different world regions has accelerated dramatically because of advances in communications and a rapid increase in economic and financial interdependence worldwide (Arnett, 2002). The United States (U.S.) is a country with a rich history of immigration from around the world (Youakim, 2004) and a recent U.S. Department of Commerce Census (2010) indicated 1 in 8 U.S. residents were foreign-born. As economic and cultural globalization continues, migration streams related to international marriages are expected to keep growing (H. Lee, 2008). In the United States, the foreign-born population rose from 9.6 million in 1970 to 31.1 million in 2000. In 2009, it surpassed 38.5 million. Furthermore, the likelihood of a relationship between international individuals is increasing as $59.7 \%$ of the foreign-born population in the United States (ages 15 and up) is married (U.S. Census, 2009). Given the demographic projections for the next 50 years, it is likely that international relations will continue to increase substantially (Frame, 2003), and a concomitant increase in international marriages will result.

Research results indicate that spouses in unsatisfactory marriages report greater levels of physical and mental health problems compared to those who find their marriage satisfactory (Levenson, Carstensen, \&

\footnotetext{
${ }^{*}$ The author would like to thank David Sarnoff, Bruce Fischer, Nancy Huenefeld and Jane Rosen-Grandon for their subject matter expertise.

Stephanie J. Thorson-Olesen, Assistant Professor, Doctorate in Psychology, Department of Psychology, Viterbo University.
} 
Gottman, 1993). Additionally, marital dissolution is often found to be a painful and agonizing experience; children who are involved can feel overwhelmed by the division of their family (Kaslow, 2001). As a result, an important challenge for practitioners and evaluation researchers is to develop interventions that produce stronger effects to promote relationship stability and quality (Hawkins et al., 2008). Furthermore, practitioners should develop strategies and techniques that are consistent with the needs of diverse clients. C. C. Lee (1997) suggested that cultural differences are real and must be actively considered essential to interventions. This type of research could open up doors for therapists to distinguish between client patterns that are universal (common to a wide variety of families), culture-specific (common to a group), or idiosyncratic (unique to that particular couple, I. Goldenberg \& H. G. Goldenberg, 2004).

Immigration and marriage are two key life events that typically take place in close relation to each other. For example, it is common for a couple to marry and immigrate to one person's homeland, or for a recent immigrant to marry a native of the new country. In marriage and immigration, the individuals are making a commitment not only to each other, but also to a new environment and world. Yet, little has been written about marriage in the context of immigration (Youakim, 2004).

When people think of international marriage, they often think of "mail order" brides (Chin, 1994). In South Korea, brokerage firms for international marriage have become a lucrative business that requires little initial investment. Since the 1990s, immigrant foreign spouses have become a visible population in South Korea and, together with the larger population of immigrant laborers; they have challenged the long-held image of a homogenous society. By 2005, 13.6\% of marriages in South Korea involved a foreign spouse, revealing a drastic increase in international marriage. The percentage of total marriages that involved a foreign spouse increased threefold over a 4-year period between 2001 and 2005. It is suggested that government regulations overseeing this sector have fallen behind and these activities are virtually uncontrolled, though the government has promised legislation regarding the citizenship of children of cohabitating international couples $(\mathrm{H}$. Lee, 2008).

Mail-order brides are only a subset of the internationally married population. Thousands of families have emigrated from their native lands to foreign terrain seeking an escape from persecution or poverty, or seeking an opportunity for a better life. Issues such as political strife, war, starvation, drug trafficking, and so forth can wreak havoc in the personal lives of families, causing them to relocate to new lands (Kaslow, 2001). However, technology, communication, economic development, and opportunities for work, study, and travel are also helping to decrease progressively the gaps between diverse people (Estrada, Burnett, \& Molina, 2004; Imamura, 1990). In today's world of multinational business and travel, the odds of pairing up with an individual from a different country and culture are higher than ever (Filisko, 2010). This growing awareness of a new global inter-connectedness is prompting efforts to reconfigure interactions across social boundaries (C. C. Lee, 1997).

The term "trans-cultural" represents the new family culture that is created when the cultures of two people from different backgrounds intersect to form a new culture. One of the first important decisions that an inter-cultural couple from different countries of origin face is determining a place of residence. Furthermore, intercultural couples have a higher probability than same culture couples to encounter differences in parenting beliefs and practices, based on their respective cultural backgrounds, values, and worldviews. Additionally, it was found that intercultural couples have several additional layers of complexity in comparison to mono-cultural couples. Consistent with increasing demographic trends, researchers have called out a need for more information pertaining to diverse populations (Crippen \& Brew, 2007). Many scholars agreed that therapy 
for cross-cultural couples can follow the same general principles as traditional couple's therapy, but special considerations need to be given to the unique difficulties and challenges facing cross-cultural couples (Crippen \& Brew, 2007).

The terms "international" and "cross-national" marriage are used to emphasize couples that differ in their nationality (Cavallaro \& Seto, 2007). In a world where ethnic diversity is increasing, more and more couples of differing cultural backgrounds are choosing to marry. The cultural differences between individuals who marry raise unique concerns. Couples who enter an international marriage learn very quickly how their differences can be the catalyst for either excitement or conflict. In some couples, this might mean that one partner submits to the other's cultural practices and relinquishes his or her own. More effectively, the goal is for international couples to celebrate each other's cultural practices or blend them to create new traditions that honor both of their cultures (Frame, 2003).

The unprecedented volume and character of contemporary international migrations provides exceptional opportunities for researchers (Rogler, 1994). International couples often have to overcome differences as small as cups versus milliliters in the kitchen, Fahrenheit versus Celsius outdoors, and as large as deciding whose homeland to reside in and navigating visas, green cards, and citizenship through a complicated and sometimes confusing immigration process. As economic and cultural globalization expands, and migration streams escalate, the odds of pairing up with an individual from a different culture and country are higher than ever (Filisko, 2010; H. Lee, 2008). Yet, little attention has been given to mixed nationality (international) couples (Imamura, 1990; Rehman \& Holtzworth-Munroe, 2007). As a result, there is a great need for the development of culturally competent individual, family, community, and organizational level intervention strategies for immigrants (Youakim, 2004). Additionally, research of this nature might foster a continued sense of social responsibility and activism within the profession to take multicultural considerations into account and positively impact future research and practices. Kaslow (2001) suggested that there is a need for family psychologists to share and exchange information that crosses national borders to augment the knowledge base and enhance intervention skills. Furthermore, there is a dire need for more research and clinical attention to investigate the breadth and complexity of these marriages. Understanding international/cross-national couples requires therapists to broaden their cultural competency within a global context (Cavallaro \& Seto, 2007). The findings of this research assist in identifying whether the areas of targeted intervention are similar for domestic and international couples or if special considerations need to be addressed. To address the unique issues that international couples face, this study was conducted to understand whether or not there are differences in marital values and satisfaction between domestic and international couples. Marriage satisfaction has become a central construct, which serves as a cornerstone for understanding how marriages work (Funk \& Rogge, 2007); therefore, measures of satisfaction were deemed a reasonable starting point for examining this population.

\section{Methodology}

An online quantitative survey was utilized to determine if there was a statistically significant difference in the variables of interest, depending on couple type. The format of the data collected supported the descriptive, correlational design that was used to test the study hypotheses. For the purposes of this study, "values" are defined as the level of importance an individual places on a marital characteristic. Furthermore, "marital satisfaction" is characterized as the subjective evaluation of an individual's marriage. Marital satisfaction is considered a relatively stable attitude and attribute that refers to the degree to which an individual's needs, 
expectations, and desires are being met within the relationship (Rosen-Grandon, 1998).

The population studied consisted of individuals from heterosexual married couples and were classified into two different groups: (1) domestic (both individuals are natives of the United States); and (2) international (one partner is a native of the United States and the other is foreign-born). The sample was one of convenience, recruited with flyers. In addition, a snowball-referral technique was used to recruit participants.

Respondents were directed to a demographic form, which was then followed by the Characteristics of Marriage Satisfaction Inventory (CHARISMA; Rosen-Grandon, 1998). There were 18 items on a six-point Likert scale concerning marital values. The same items were then addressed in terms of marital satisfaction. Item number 37 was an overall rating of marital satisfaction, which was not used for the purposes of this research study. The CHARISMA inventory was developed at the University of North Carolina at Greensboro (Rosen-Grandon, 1998) and has since been used with hundreds of individuals and couples as a clinical tool in therapy, for marital education, and research. Furthermore, it has been found that the CHARISMA marriage satisfaction inventory is easily applicable to cross-cultural studies of marital satisfaction because of the verbal simplicity (Rosen-Grandon, 1998).

\section{Results}

Eighty participants contributed to the results (41 male; 39 female). Ninety six percent identified themselves as white. When asked about religious affiliation, 36\% indicated not religious. Seventy-seven percent were in their first marriage with 43\% married for 3-9 years. Marriage type consisted of American-American $(N=23)$, American-Foreign $(N=29)$ and Foreign-American $(N=28)$.

There were six primary research questions. Research Questions 1-3 focused on marital values. Specifically, the first research question focused on whether marital values (satisfaction with love, loyalty, and family values) differed based on gender. Since the results of the MANOVA examining the effect of gender were non-significant, it was decided that gender did not have a significant effect on marital values; therefore, the null hypothesis was retained. The second research question looked at whether marital values (satisfaction with love, loyalty, and family values) differed based on marriage type. This analysis found a significant result, indicating that marriage type played a role in marriage values. Furthermore, a follow-up analysis indicated that the mean family values $(M=11.86, S D=3.821)$ for domestic participants with American spouses were significantly higher than the score for foreign participants with American spouses $(M=8.89, S D=3.445)$. Therefore, the null hypothesis was rejected in favor of the alternative hypothesis. The third research question asked whether marital values (satisfaction with love, loyalty, and family values) differed by marriage type, dependent on gender. The result of the MANOVA examining the interaction of marriage type and gender was non-significant, thus it was implied that marital values were not significantly affected by marriage type depending on gender.

Research Questions 4-6 focused on marital satisfaction. Specifically, research question 4 focused on whether marital satisfaction (satisfaction with love, loyalty, and family values) differed based on gender. In the analysis of gender the mean family values score for American participants with American spouses found a non-significant effect on the combined marital satisfaction variable, but indicated a significant effect on loyalty. The mean loyalty score for male participants $(M=16.927, S D=1.212)$ was significantly lower than the mean loyalty score for female participants $(M=17.486, S D=.887)$. As a result, the null hypothesis was rejected in favor of the alternative hypothesis in accordance with the effect of gender on marital satisfaction with loyalty. Research question 5 focused on whether marital satisfaction (satisfaction with love, loyalty, and family values) 
differed based on marriage type. The MANOVA examining the effect of marital type was non-significant, therefore, it was implied that marital type did not have a significant effect on marital satisfaction. Research question 6 concerned whether marital satisfaction (satisfaction with love, loyalty, and family values) differed by marriage type, dependent on gender. The MANOVA examining the interaction of marriage type and gender was non-significant, therefore, it was implied that marital satisfaction was not significantly affected by marriage type depending on gender and the alternate hypothesis was rejected.

\section{Discussion}

The results showed that domestic (American with American spouse) and international (foreign with American spouse) marriages view marital values differently. Less importance was placed on the specific construct of family values (good parenting, faith in God, and religious commitment) in international marriages as compared to domestic marriages. However, there was no difference between domestic and international marriages when it came to marital satisfaction. As a result, the significant findings related to marital values become even more interesting since the alternate hypothesis of marital satisfaction was rejected (no difference) for the two different types of marriages.

These findings are relatively consistent with the overall findings in a research study by Myers, Madathil, and Tingle (2005) in which the CHARISMA marriage satisfaction inventory was used to investigate the marriage satisfaction of couples in India and the United States while comparing arranged marriages and marriages of choice. Differences were found in the importance of marital characteristics (also called marital values) but not in satisfaction. However, the difference in marital values was found to be due to the pathways of love and loyalty rather than family values. Each group, in terms of importance (or value) to the marriage, viewed the pathways differently. However, it confirmed the findings that values do not discriminate between groups when marriage satisfaction is considered (Myers et al., 2005).

The finding that international married (foreign with American spouse) participants placed less importance on family values (good parenting, faith in God, and religious commitment) was surprising because it has been implied that religion has a strong impact on satisfaction (Lopez, Riggs, Pollard, \& Hook, 2011). Research studies have indicated that there is a strong relationship between religiosity and marital stability. Furthermore, findings suggest that when both spouses attend church regularly, the couple has the lowest risk of divorce and spousal differences (Lopez et al., 2001). However, perhaps leaving their homeland, family and relocating to a new land and life demands greater flexibility and a different sense of open-mindedness. Furthermore, it was found that men are less satisfied with the loyalty pathway (lifetime commitment, loyalty, and strong moral values) with their spouses. The findings also suggest that marital satisfaction did not differ by marital type, dependent on gender. This suggests that regardless of whether the men were in a domestic or international marriage, they were less satisfied with loyalty.

Even though efforts were made to produce a valid study, limitations did exist. The generalizability could be questioned because nearly all participants were White and participants had to have access to the Internet for the online survey. Furthermore, nationality was not explored further than the two groups (domestic and international) and country of origin and acculturation could potentially make a difference. A more diverse sample from across the United States would be the most ideal for a future research design. Due to limited resources and this study's exploratory nature, the researcher did not distinguish nationalities or seek specific nationalities. For example, this particular study did not take into account the difference between Norwegians, 
Australians, Korean, and so forth. Additionally, the focus was strictly on couples that were currently residing in the United States. The sampling technique also presented limitations to validity, as it was a sample of convenience along with a snowball sampling technique, as opposed to random sampling. The sole means of data collection relied on a self-report instrument. Additionally, a combination of surveys could add breadth and depth to the data collection.

Due to the limited knowledge about internationally married couples, a design consideration such as conducting qualitative research might be beneficial to learn more about the personal narratives and themes of these unique relationships and the challenges that occur as a result of one individual living in another's homeland, navigating immigration, and integrating into a new society. Another recommendation for future designs would be to perform a more intricate item-by-item analysis to check for specific differences in marital values and satisfaction. Furthermore, the findings suggest that family values were rated as less important to international couples as compared to domestic couples. It could be worthwhile to understand further the role of parenting, faith in God, and religious commitment to these couples. Replication of the study with a larger and more representative sample is needed to examine further the findings. Furthermore, for the purpose of this study participants were either in a domestic or international marriage but the specific nationality was not known and was not a focal point. Future research should examine variations dependent on nationality and acculturation.

\section{Conclusion}

In this study the marital values and satisfaction of domestic and internationally married people living in the United States were explored, while also examining gender as an independent variable. A quantitative research analysis was used to investigate the questions. The findings suggested that there is a difference in marital values between domestic and international married couples, although there was no significant difference in marital satisfaction. Furthermore, men were found to have lower satisfaction with the loyalty pathway, regardless of whether they were in a domestic or international marriage. Replicating this research employing larger samples might reveal more detailed within-group differences. Further research on domestic and international marriages is needed to understand more fully these relationships in order to provide a knowledge base for practitioner competency so that married couples are more appropriately served.

\section{References}

Arnett, J. J. (2002). The psychology of globalization. American Psychologist, 57(10), 774-783. doi:10.1037/0003-066X.57.10.774

Cavallaro, M., \& Seto, A. (2007). Cross-national couples in the mainland United States. The Family Journal, 15(3), $258-264$. doi: $10.1177 / 1066480707301315$

Chin, K. (1994). Out-of-town brides: International marriage and wife abuse among Chinese immigrants. Journal of Comparative Family Studies, 25(1), 53.

Crippen, C., \& Brew, L. (2007). Intercultural parenting and the transcultural family: A literature review. The Family Journal, 15(2), 107-115. doi:10.1177/1066480706297783

Estrada, D., Burnett, J. A., \& Molina, B. (2004). Cultural communities: Challenges and opportunities in the creation of "happily ever after" stories of intercultural couplehood. The Family Journal, 12(2), 139-147. doi:10.1177/1066480703261962

Filisko, G. M. (2010). When global families fail: As family takes on global dimensions, international treaties may hold the key to resolving disputes. ABA Journal, 96(7), 56.

Frame, M. W. (2003). The challenges of intercultural marriage: Strategies for pastoral care. Pastoral Care, 52(3), $219-232$. doi:10.1023/B:PASP.0000010024.32499.32

Funk, J. L., \& Rogge, R. D. (2007). Testing the ruler with item response theory: Increasing precision of measurement for relationship satisfaction with the couples satisfaction index. Journal of Family Psychology, 21(4), 572-583. doi:10.1037/0893-3200.21.4.572 
Goldenberg, I., \& Goldenberg, H. G. (2004). Family therapy: An overview (6th ed.). Pacific Grove, C.A.: Brooks/Cole-Thomson Learning.

Hawkins, A. J., Blanchard, V. L., Baldwin, S. A., \& Fawcett, E. B. (2008). Does marriage and relationship education work? A meta-analytic study. Journal of Consulting and Clinical Psychology, 76(5), 723-734. doi:10.1037/a0012584

Imamura, A. E. (1990). Strangers in a strange land: Coping with marginality in international marriage. Journal of Comparative Family Studies, 21(2), 171.

Kaslow, F. W. (2001). Families and family psychology at the millennium: Intersecting crossroads. American Psychologist, 56(1), 37-46. doi:10.1037/0003-066X.56.1.37

Lee, C. C. (1997). Multicultural issues in counseling: New approaches to diversity (2nd ed.). Alexandria, V.A.: American Counseling Association.

Lee, H. (2008). International marriage and the state in South Korea: Focusing on governmental policy. Citizenship Studies, 12(1), 107-123. doi:10.1080/13621020701794240

Levenson, R., Carstensen, L., \& Gottman, J. (1993). Long-term marriage-Age, gender, and satisfaction. Psychology and Aging, 8(2), 301-313. doi:10.1037/0882-7974.8.2.301

Lopez, J. L., Riggs, S. A., Pollard, S. E., \& Hook, J. N. (2011). Religious commitment, adult attachment, and marital adjustment in newly married couples. Journal of Family Psychology, 25(2), 301-309. doi:10.1037/a0022943

Rehman, U. S., \& Holtzworth-Munroe, A. (2007). A cross-cultural examination of the relation of marital communication behavior to marital satisfaction. Journal of Family Psychology, 21(4), 759-763. doi:10.1037/0893-3200.21.4.759

Rogler, L. H. (1994). International migrations: A framework for directing research. American Psychologist, 49(8), $701-708$. doi:10.1037/0003-006X.49.8.701

Rosen-Grandon, J. R. (1998). CHARISMA: The characteristics of marriage inventory. Greensboro, N.C.: Author.

U.S. Census Bureau. (2009). 2005-2009 American Community Survey 5-year estimates. Retrieved from http://factfinder.census. gov/servlet/STTable?_bm=y\&geo_id=01000US\&-qr_name=ACS_2009_5YR_G00_S1201\&ds_name=ACS_2009_5YR_G0 0

U.S. Department of Commerce, Economics and Statistics Administration, U.S. Census Bureau. (2010). Place of birth of the foreign-born population: 2009. Retrieved from http://www.census.gov/prod/2010pubs/acsbr09-15.pdf

Youakim, J. M. (2004). Marriage in the context of immigration. The American Journal of Psychoanalysis, 64(2), 155-165. doi:10.1023/B:TAJP.0000027270.81747.f7 